\title{
The effect of electrical properties for InGaN and InN by high-energy particle irradiation (Notice of Removal)
}

Shao-guang Dong, Guang-han Fan

Shao-guang Dong, Guang-han Fan, "The effect of electrical properties for InGaN and InN by high-energy particle irradiation (Notice of Removal)," Proc. SPIE 6841, Solid State Lighting and Solar Energy Technologies, 68411H (4 January 2008); doi: 10.1117/12.756628

SPIE. Event: Photonics Asia 2007, 2007, Beijing, China 


\title{
The effect of electrical properties for I $\mathrm{nGaN}$ and I $\mathrm{nN}$ by high-energy particle irradiation (Notice of Removal)
}

\author{
Proc. SPIE 6841, 68411H (2008); http://dx.doi.org/10.1117/12.756628 \\ Online Publication Date: 4 J anuary 2008 \\ Retracted from Publication: 8 August 2008 \\ Conference Date: 12 November 2007 \\ Conference Location: Beijing, China \\ Conference Title: Solid State Lighting and Solar Energy Technologies \\ Conference Chairs: J inmin Li, Yubo Fan, Ling Wu, Yong-Hang Zhang, Michael E. Coltrin, Yuwen Zhao, \\ Nuofu Chen, Vladimir M. Andreev, Jai Singh
}

\section{Shao-guang Dong}

South China Normal Univ. (China) and Foshan Univ. (China)

Guang-han Fan

South China Normal Univ. (China)

This paper (SPIE Paper $68411 \mathrm{H}$ ) was removed from the SPIE Digital Library on 8 August 2008 upon discovery that the paper has substantially plagiarized the following two papers:

R.E. Jones, S.X. Li, L. Hsu, K.M. Yu, W. Walukiewicz, Z. Liliental-Weber, J.W. Ager III, E.E. Haller, H. Lu, and W.J. Schaff, "Native-defect-controlled n-type conductivity in InN," Physica B 376-377 (2006) 436- 439

and S.X. Li, K.M. Yu, J. Wu, R.E. Jones, W. Walukiewicz, J.W. Ager III, W. Shan, E.E. Haller, Hai Lu, and William J. Schaff, "Native defects in InxGa1-xN alloys," Physica B 376-377 (2006) 432-435.

As stated in the SPIE Publication Ethics Guidelines, "SPIE defines plagiarism as the reuse of someone else's prior ideas, processes, results, or words without explicit attribution of the original author and source, or falsely representing someone else's work as one's own. Unauthorized use of another researcher's unpublished data or findings without permission is considered to be a form of plagiarism even if the source is attributed. SPIE considers plagiarism in any form, at any level, to be unacceptable and a serious breach of professional conduct."

It is SPIE policy to remove such papers and to provide citations to original sources so that interested readers can obtain the information directly from those sources.

One of the authors, Shao-guang Dong, accepts full responsibility and apologizes for this plagiarism and has absolved the second author, Guang-han Fan, of any prior knowledge of or professional misconduct in this matter. Guang-han Fan also states that he had not previously seen the paper or given permission to include his name as an author. 